23

\title{
Исследование особенностей регистрации оптического отклика рентгеновских люминофоров для рентгеновской фотодинамической терапии
}

\author{
(C) П.В. Медведев, И.А. Панкин , М.А. Солдатов, О.Е. Положенцев, А.В. Солдатов \\ Международный исследовательский институт интеллектуальных материалов, Южный федеральный университет, \\ 344090 Ростов-на-Дону, Россия \\ ฯ e-mail: pmedvedev@sfedu.ru
}

Поступила в редакцию 15.10.2021 г.

В окончательной редакции 02.12.2021 г.

Принята к публикации 02.12.2021 г.

\begin{abstract}
Приведено описание установки для исследования оптического отклика рентгеновских люминофоров, рассматриваемых в качестве составной части композитных материалов для рентгеновской фотодинамической терапии. Представлены концепция и основные принципы рентгеновской фотодинамической терапии. Приведены результаты тестовых испытаний разрабатываемой установки, обсуждены способы оптимизации соотношения сигнал/шум путем варьирования параметров источника рентгеновских лучей и оптимизации геометрии эксперимента. Рассмотрены примеры измерений сигнала люминесценции, возбуждаемой рентгеновским излучением, для концентрированных порошкообразных образцов и разбавленных образцов в форме коллоидных растворов.
\end{abstract}

Ключевые слова: активные формы кислорода, фотосенсибилизатор, перенос энергии.

DOI: 10.21883/OS.2022.03.52178.2829-21

\section{Введение}

Концепция и принципы рентгеновской фотодинамической терапии

Первые попытки применения фотоактивных веществ при взаимодействии со светом для лечения заболеваний кожи, таких как витилиго, рахит, псориаз и даже раковые заболевания кожи, известны еще со времен древнего Египта, Китая и Индии $[1,2]$. За последние полвека, начиная с 1960 г., когда Lipson и Baldes [3] продемонстрировали регрессию опухолевых тканей после введения порфиринов и последующего их облучения видимым светом, был проведен ряд исследований с целью выяснения механизмов, приводящих к гибели клеток в результате фотодинамической терапии (ФДТ). Так, в работе Doughery и др. было продемонстрировано успешное применение ФДТ для диагностирования и лечения рака легких, пищевода, толстого кишечника, брюшины, мочеполовой системы, мозга, органов зрения и кожи $[1,4]$.

Механизм действия фотодинамической диагностики и терапии подразумевает использование трех основных компонент: фотосенсибилизатора (ФС), источника излучения в оптическом диапазоне и кислорода, содержащегося в тканях [1]. Под воздействием возбуждаемого излучения в ультрафиолетовой или видимой области спектра, частицы ФС сначала переводятся в синглетное возбужденное состояние, а затем в триплетное возбужденное состояние, таким образом приобретая способность электронного переноса и дальнейшего формирования активных форм кислорода (АФК) І-типа или II-типа путем передачи избытка энергии триплетным формам кислорода ${ }^{3} \mathrm{O}_{2}$, которые должны быть расположены в непосредственной близости от частиц ФС $[5,6]$. Сегодня ФДТ повсеместно используется для лечения различных дерматологических заболеваний, а также при лечении не глубоко расположенных опухолей [7-9], однако ее основным ограничением является невозможность применения данного метода для глубоколежащих опухолей и метастаз, ввиду ограниченного проникновения возбуждающего оптического или УФ луча в ткани. В последние десятилетия большой импульс в развитии получил метод рентгеновской ФДТ (X-ray Photo-Dynamic Therapy, ХPDT), призванный преодолеть вышеобозначенные ограничения метода ФДТ и осуществить возможность терапии заболеваний глубоко расположенных тканей и опухолей $[5,10,11]$.

Хотя концепция рентгеновской ФДТ была предложена в середине 1950-х годов [12,13], практическое использование данного метода сдерживалось двумя факторами. Во-первых, отсутствием возможности формирования интенсивных и сфокусированных рентгеновских и/или гамма-пучков в медицинских установках. В настоящее время эта проблема уже решена и в практической медицине широкое распространение получили установки, использующие гамма-излучение, генерируемое либо изотопными источниками, например $\mathrm{Co}^{60}$, либо высокоэнергетическими ускорителями электронов [10,14-16]. Вторым фактором, сдерживающим реальное использование принципа рентгеновской ФДТ, является отсутствие в настоящее время допущенных к применению эффективных препаратов, которые при облучении жестким 


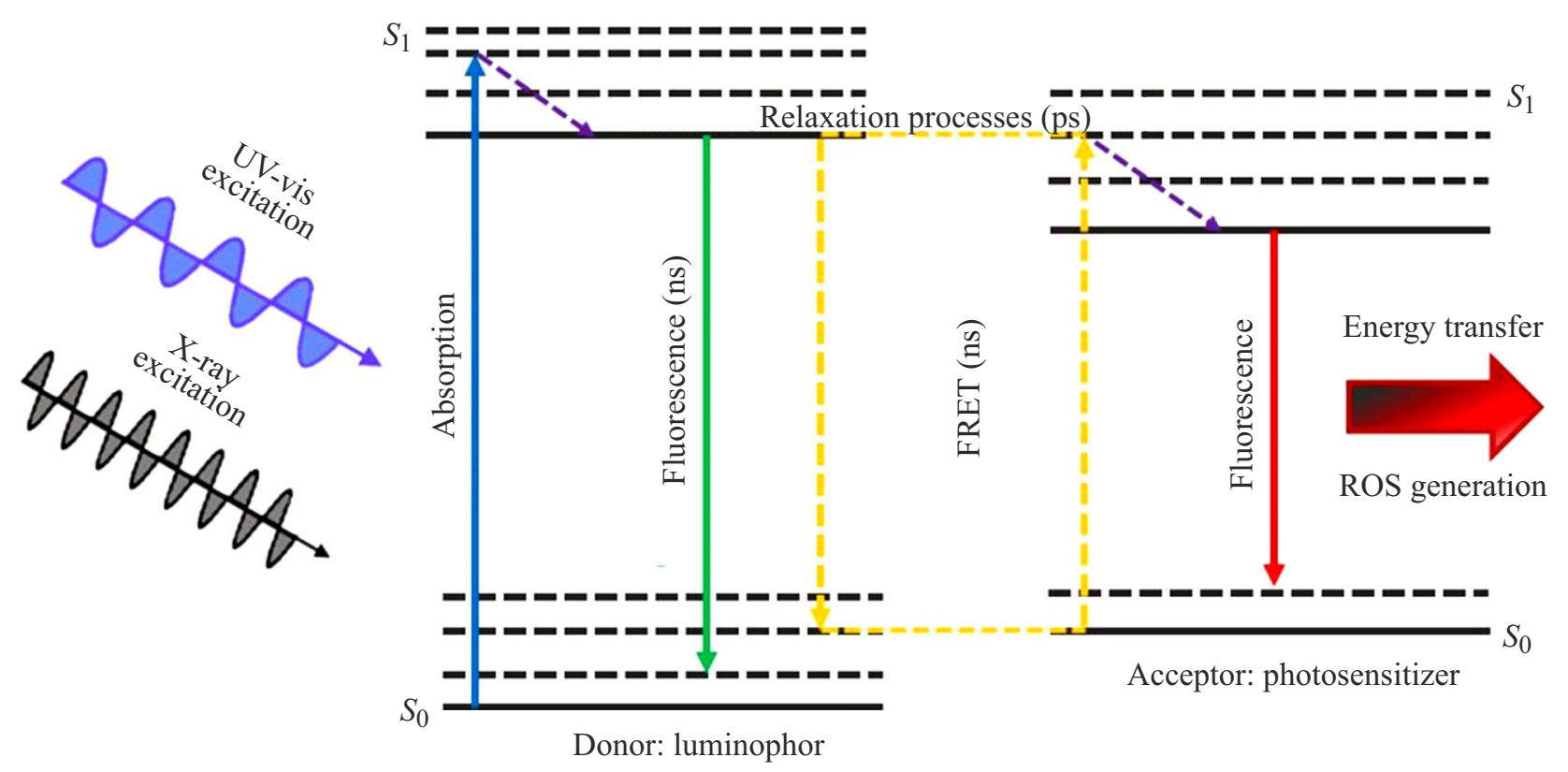

Рис. 1. Схематическое изображение переноса энергии при реализации рентгеновской фотодинамической терапии ХPDT с использованием рентгенлюминофоров. В левой части рисунка показаны энергетические уровни рентгенлюминофора, в правой части - фотосенсибилизатора. Сплошные линии соответствуют основному и возбужденному состояниям $\left(S_{0}\right.$ и $\left.S_{1}\right)$, в то время как штриховые линии соответствуют возможным расщеплениям основного и возбужденного состояний. Обмен энергией между люминофором и фонсенсибилизатором может происходить как с помощью излучения и поглощения оптических фотонов, так и с помощью ферстеровского переноса (FRET). Оранжевые вертикальные линии соответствуют излучению и поглощению виртуальных фотонов. Для наглядности в левой части рисунка показано, что аналогичные переходы имеют место при возбуждении УФ.

(рентгеновским или гамма) излучением вызывали бы появление в окружающих их биологических тканях активных форм кислорода.

Принцип рентгеновской ФДТ заключается в том, что инициирование процесса генерации АФК происходит за счет первичного возбуждения частиц рентгенолюминофоров с помощью рентгеновского или гамма-излучения и последующего переноса энергии от частиц рентгенлюминофоров к фотосенсибилизатору, которое может осуществляться как за счет переизлучения энергии, поглощенной в виде рентгеновских лучей рентгенолюминофорами, в оптическом или УФ диапазоне, так и с помощью фёрстеровского механизма, подразумевающим прямой диполь-дипольный перенос между двумя хромофорами без испускания оптических фотонов [17] (рис. 1). Таким образом, исследование оптических свойств рентгенолюминофора (РФ) и фотосенсибилизатора (ФС) является важнейшим этапом в проектировании и синтезе новых материалов для рентгеновской фотодинамической терапии. Для оптимального переноса энергии основным критерием является перекрывание спектров флуоресценции люминофоров и спектра поглощения ФС.

\section{ХЕОL спектроскопия}

Оптический отклик рентгенолюминофоров при возбуждении рентгеновским излучением исследуют с помощью XEOL- (X-ray Excited Optical Luminescence) спектроскопии. Возникновение XEOL-сигнала представ- ляет из себя процесс передачи энергии, в котором поглощение рентгеновского фотона приводит к образованию определенного количества фото- и оже-электронов, которые, в свою очередь, приводят к дальнейшим возбуждениям. В общем случае энергия передается центрам люминесценции за счет неупругих процессов, что приводит к созданию дырок в валентной зоне и электронов в зоне проводимости в полупроводниковых структурах, или электронно-дырочных пар на свободных и занятных молекулярных обителях органических молекул [1]. Процесс рекомбинации дырок и электронов будет приводить к испусканию оптических фотонов сцинтилляционный процесс.

Помимо исследования оптического отклика на возбуждение ионизирующим излучением, XEOL-сигнал позволяет исследовать оптический спектр испускания флуоресценции рентгенолюминофоров, что является необходимым этапом для подбора подходящего фотосенсибилизатора при разработке композитных материалов для рентгеновской фотодинамической терапии. XEOL-сигнал в комбинации с другими типами рентгеновской спектроскопии, например, околопороговой тонкой структуры XANES (X-ray Absorption Near Edge Structure) или протяженной тонкой структуры спектров рентгеновского поглощения EXAFS (Extended X-ray Absorption Fine Structure) в последние годы эффективно используется для исследования природы и 
механизмов оптической люминесценции в различных материалах [18-23], а также в качестве способа мониторинга радиоактивного повреждения образцов в рентгеноструктурном анализе белков [24] и высвобождения лекарственных препаратов из наноконтейнеров при варьировании кислотности среды (рН-индуцированное высвобождение) [25]. Недавние применения данной методики позволяют проводить исследования в пикосекундном диапазоне $[22,26]$, а также осуществлять картирование по поверхности образца в рамках методики $2 D$ XAFS-XEOL $[27,28]$. Ввиду высокой проникающей способности рентгеновского излучения в последние годы XEOL-спектроскопия привлекает большой исследовательский интерес для исследования оптического отклика рентгеновских люминофоров, используемых в рентгеновской фотодинамической терапии опухолей.

В настоящей работе мы представляем описание конструктивных особенностей и результаты тестирования лабораторного стенда для исследования XEOL-сигнала рентгенолюминофоров в порошковой форме и в форме коллоидных растворов. В работе приведены результаты тестовых измерений, определены оптимальные параметры и геометрия эксперимента.

\section{Описание измерительного стенда и конструктивные особенности}

В данном разделе представлено описание конструкутривных особенностей разработанного стенда для XEOL-характеризации рентгеновских люминофоров в порошковообразной и жидкой фазах. Рассматриваемая в статье установка является существенно доработанным вариантом ранее кратко описанного в литературе прототипа [29]. Основной отличительной особенностью новой установки является использование более мощной и имеющей значительно более широкий диапазон ускоряющего напряжения (от 30 до $90 \mathrm{kV}$ ) рентгеновской трубки РАП90-5. При этом большая мощность рентгеновского источника, используемая в разработанном стенде, требует существенно более внимательного отношения к вопросу защиты от ионизирующего излучения.

В настоящей установке радиационная защита обеспечена двухуровневой системой защиты. Первый уровень защиты осуществляется внешним свинцовым кожухом. Каркас кожуха состоит из алюминиевого экструзионного профиля шириной $30 \mathrm{~mm}$, в пазы которого устанавливаются покрытые защитной пленкой листы свинца толщиной $5 \mathrm{~mm}$ (пленка препятствует распростарнению мелкой свинцовой пыли). Для предотвращения прохождения рассеянного рентгеновского излучения через алюминиевый профиль стыки между листами были дополнительно защищены прямоугольными лоскутами листового свинца толщиной $2 \mathrm{~mm}$. Источником рентгеновских лучей является рентгеновская трубка РАП90-5 с максимальным ускоряющим напряжением $90 \mathrm{kV}$ и расходимостью пучка $\sim 40^{\circ}$. Внутри защитного внешнего свинцового кожуха был расположен флуоресцентный спектрофотометр Сагу Eclipse (Agilent, Австралия), далее флуориметр, который позволяет регистрировать оптический отклик исследуемых рентгеновских люминофоров в диапазоне длин волн от 200 до $1100 \mathrm{~nm}$.

В разработанной установке предусмотрена возможность варьирования расстояния от выходного окошка рентгеновской трубки до исследуемого образца (рис. 2). Рентгеновская трубка расположена над кюветным отсеком флуориметра. Ввиду большой расходимости рентгеновского пучка на пути от выходного окошка рентгеновской трубки до внутреннего защитного свинцового кожуха держателя образца, для обеспечения дополнительной радиационной защиты расположен цилиндр, выполненный из листа свинца толщиной $2 \mathrm{~mm}$. В ходе регистрации рентген-возбужденной оптической флуоресценции (XEOL) жидкий или порошкообразный образец, расположеный на специальном держателе образца (рис. 2), облучается пучком рентгеновского излучения от импульсного истоника (2). Расходимость рентгеновского пучка и удаленность источника обеспечивают равномерную засветку всей поверхности порошкообразного или жидкого образца. Оптический сигнал, испущенный рентгеновским люминофором, попадает на окошко отсека детектора (3) флуориметра, где в дальнейшем проходит через коллимирующую щель устройства, усиливается с помощью фотоумножителя и попадает на детектор.

С целью защиты элементов отсека детектора флуориметра от длительной экспозиции рентгеновским излучением (при попадании прямых и рассеянных рентгеновских фотонов) был спроектирован и реализован внутренний защитный кожух (рис. 3). Внутренний кожух выполнен из листов свинца толщиной $2 \mathrm{~mm}$, из которых были вырезаны циллиндрический канал (деталь 2), и экранирующая оболочка в форме куба (детали 4, 12, 13) с длиной ребра $120 \mathrm{~mm}$. В качестве основания для свинцового цилиндра служит пластиковый цилиндр внешним диаметром $48 \mathrm{~mm}$.

Во фронтальной грани внутреннего защитного кожуха проделано отверстие для прохождения оптического сигнала от исследуемых образцов. Отверстие может быть экранировано свинцовым стеклом толщиной $10 \mathrm{~mm}$ (деталь 11 на рис. 3, свинцовый эквивалент $-2 \mathrm{~mm}$ для рентгеновских фотонов с энергией $100 \mathrm{keV}$ ) с целью защиты окошка детектора флуориметра от попадания рассеиваемых в камере внутреннего кожуха рентгеновских лучей. При этом оптический спектр для используемого рентгеновского стекла (рис. 4) в диапазоне длин волн от $200 \mathrm{~nm}$ до $1100 \mathrm{~nm}$ демонстрирует умеренное ослабление оптического сигнала до $15 \%$ при длинах волн от $450 \mathrm{~nm}$ и более. При длинах волн менее $450 \mathrm{~nm}$ наблюдается постепенное ослабление оптического сигнала. При длине волны в $380 \mathrm{~nm}$ наблюдается существенное ослабление светового потока равное $50 \%$, в то время как при длинах волн $<335 \mathrm{~nm}$ наблюдается полное поглощение оптического сигнала. Таким образом, для исследования 

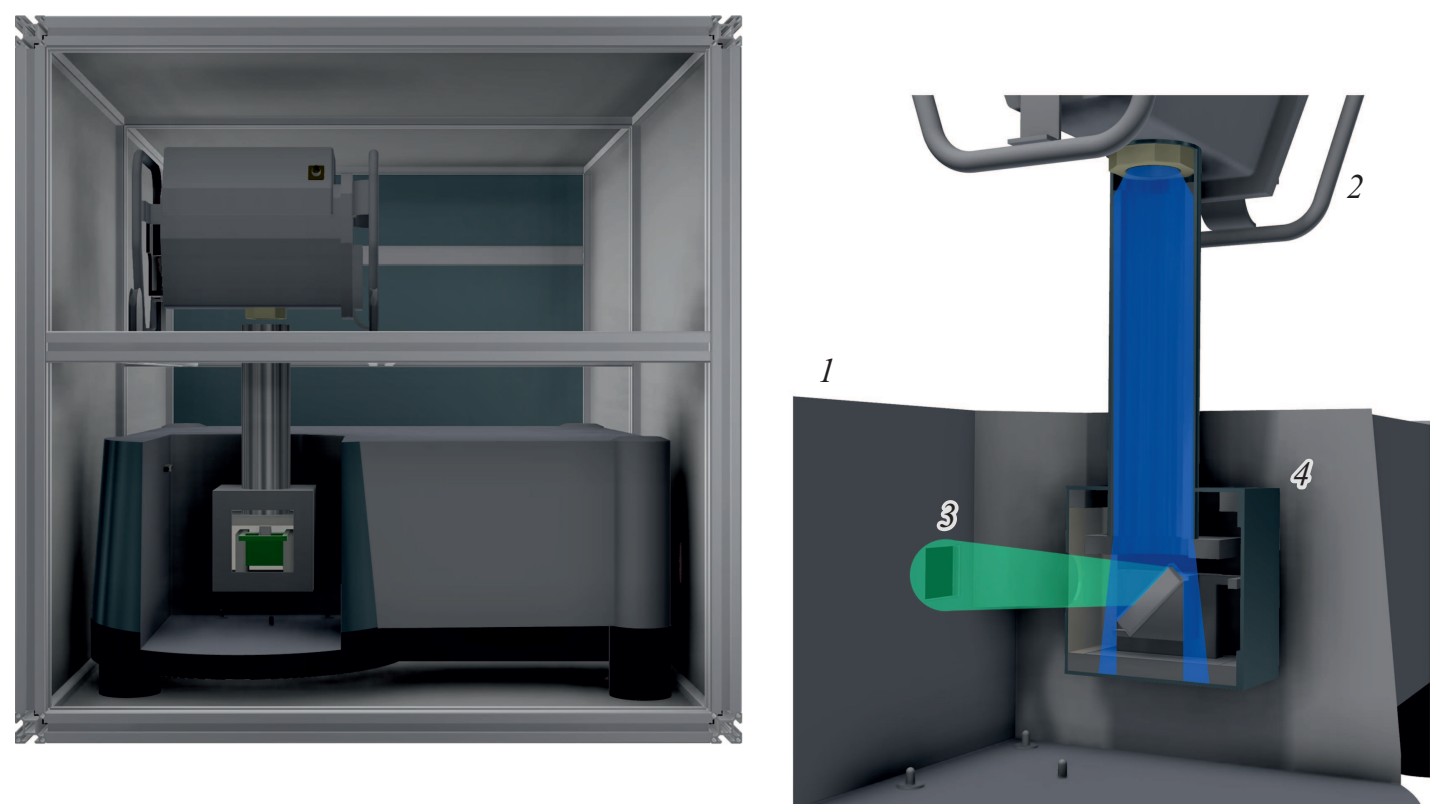

Рис. 2. Слева: общий вид установки (фронтальная часть экранирующего свинцового кожуха не показана). Справа: 1 - корпус кюветного отсека флуориметра; 2 - рентгеновская трубка; 3 - окно детектора спектрофотометра; 4 - корпус держателя образца, включающий дополнительный защитный свинцовый кожух, пластиковый корпус и непосредственно держатель образца (показан в разрезе). Падающий на образец рентгеновский пучок показан синим цветом, в то время как оптический сигнал, генерируемый исследуемым рентгеновским люминофором и попадающий в область окошка детектора спектрофотометра, показан в виде зеленого конуса.

рентгенолюминофоров, обеспечивающих оптический выход флуоресценции в фиолетовой и ультрафиолетовой области, например, люминофоров на основе $\mathrm{CeF}_{3}$ [30], использование экранирующего свинцового стекла является невозможным. Однако в ходе тестирования было показано, что отсутствие экранирования фронтального отверстия внутрненнего кожуха рентгенозащитным стеклом не приводит к заметному увеличению шумов в регистрируемом сигнале.

С тыльной стороны куба предусмотрено прямоугольное отверстие для установки исследуемых образцов, которое в режиме измерений с включенным источником рентгеновского излученя может быть закрыто накладной свинцовой дверцей (деталь 12, рис. 3), для обеспечения „замкнутости“ внутреннего защитного контура. В верхней части находится отверстие для установки свинцовой трубки, через которое рентген попадает на исследуемые образцы. Жесткость конструкции обеспечивается с помощью основания, выполненного из пластика АБС с помощью технологии $3 D$-печати - технологии послойного наплавления (детали 8 и 10 , соединенные с помощью винтов 9).

Основной функцией массивного держателя образца, показанного на рис. 3, является точное позиционирование исследуемых образцов относительно рентгеновской трубки и окошка детектора флуориметра. В связи с чем были спроектированы и в дальнейшем реализованы с использованием $3 D$ печати держатели образцов (рис. 5), которые позволяют позиционировать исследуемые об-

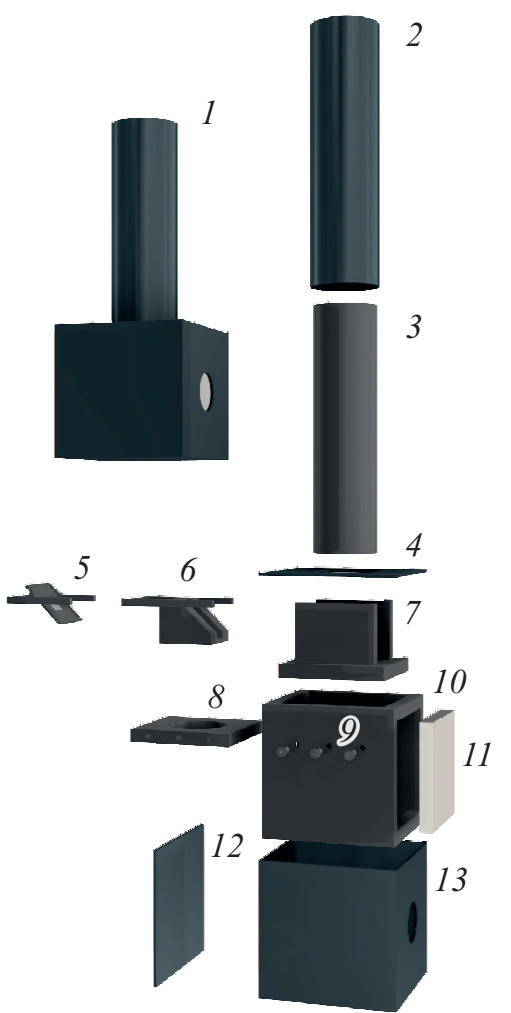

Рис. 3. Внутренний экранирующей кожух держателя образца. 1 - в сборке; 2-13 - компоненты экранирующего кожуха. 


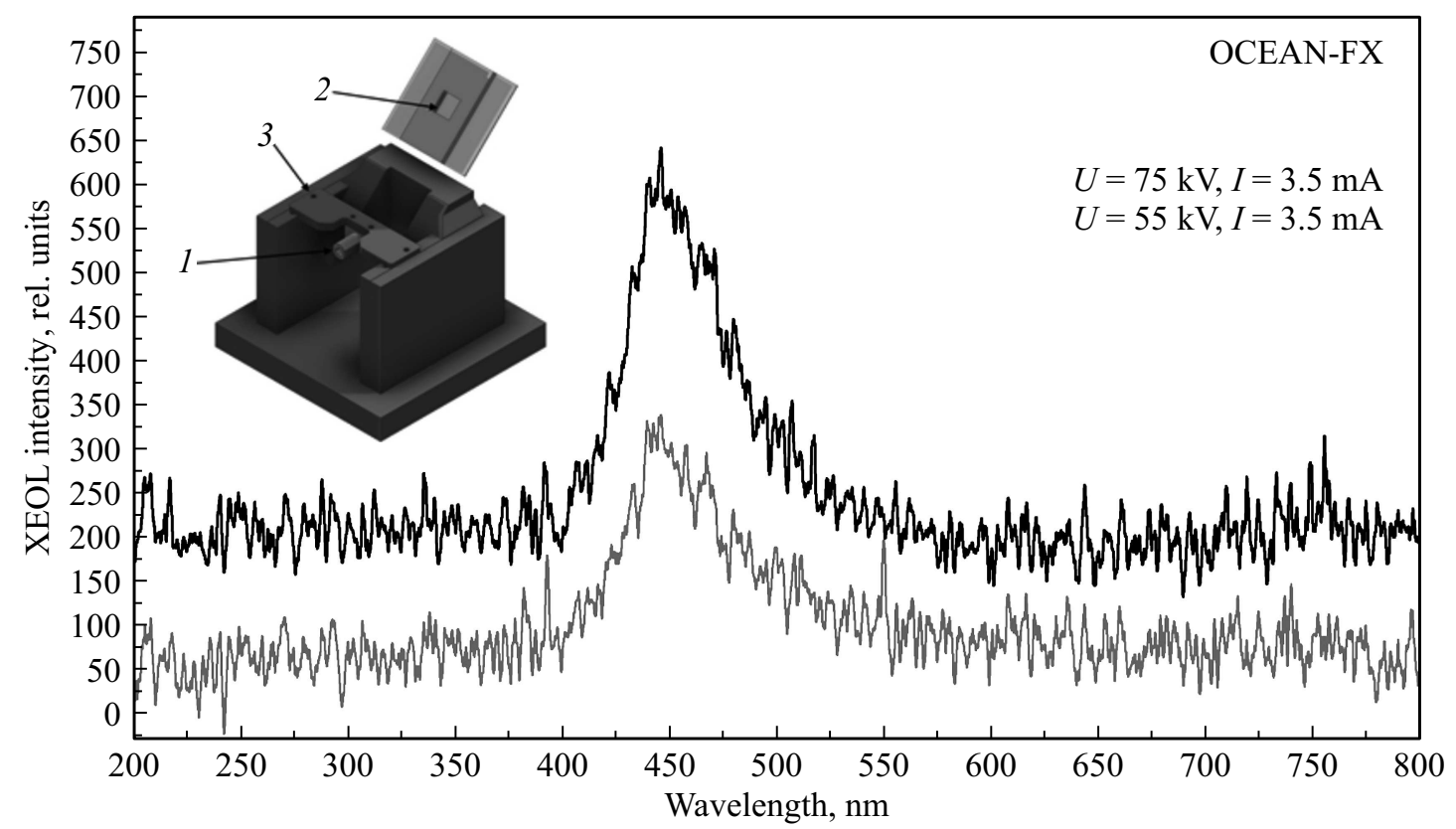

Рис. 4. Измерение оптического отклика (XEOL-сигнала) для порошкообразного коммерческого люминофора RC-450 при использовании портативного спектрометра OCEAN-FX, а также оптического волновода, позволяющего регистрировать оптический сигнал непосредственно вблизи поверхности образца. На вставке показан держатель образца, разработанный для измерений флуоресцентного сигнала с использованием оптического волновода, расположенного в непосредственной близости от поверхности образца. 1 - цилиндрический держатель, оснащенный резьбой, позволяющий однозначное позиционирование волновода относительно поверхности образца, расположенного в полости пластинки держателя образца 2. 3 - отверстия для фиксации каретки, на которой расположен фиксатор волновода, позволяющие варьировать расстояния от оптического зонда до поверхности образца.

5

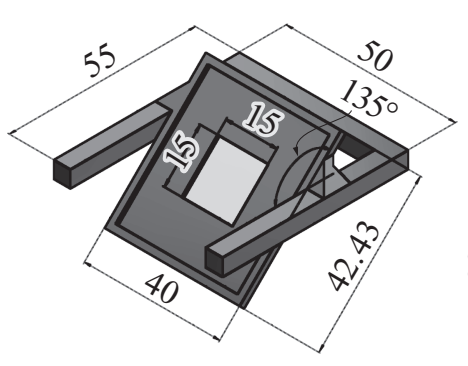

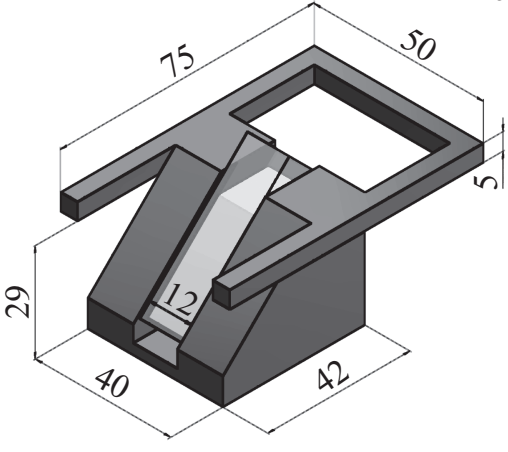

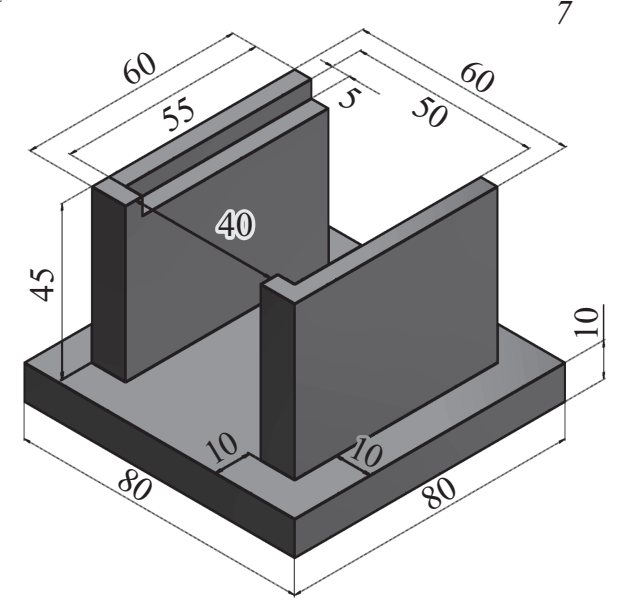

Рис. 5. 5 - держатель для порошкообразных образцов; 6 - держатель для кюветы для измерения сигнала коллоидных растворов и суспензий; 7 - платформа с рельсами для держателей порошкообразных и жидких образцов, позволяющая воспроизводимое позиционирование образца. Эти же элементы в миниатюре показаны на рис. 3 под теми же номерами.

разцы под углом $45^{\circ}$ и к направлению нормального падения рентгеновских лучей, и к плоскости окна детектора флуориметра.

Также в настоящей работе представлены результаты регистрации XEOL-сигнала с помощью портативного оптического спектрометра OCEAN-FX, с использованием специального держателя образца, обеспечивающего точное позиционирование волновода относительно поверхности образца (рис. 4).

Необходимость создания внутреннего экранирующего кожуха обосновывалась как требованием усиления радиационной защиты при работе с высокими ускоряющими напряжениями, целесообразностью защиты отсека детектора оптического флуориметра от длительного экспози- 


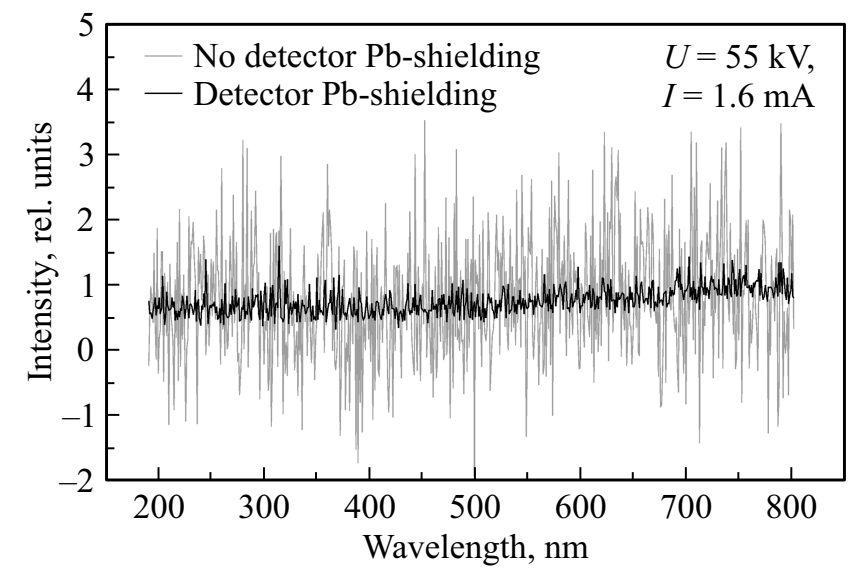

Рис. 6. Сравнение уровня шума, регистрируемого флуориметром в диапазоне длин волн от 200 до $800 \mathrm{~nm}$ при использовании внутреннего свинцового кожуха и без.

ционирования рентгеновскими лучами, так и улучшением отношения сигнал/шум. На рис. 6 показан эффект экранирования установки с использованием внутреннего защитного кожуха, а также цилиндрической свинцовой трубки, расположенной на пути от окошка рентгеновской трубки до входного отверстия внутреннего защитного кожуха. Можно видеть, что экранирование приводит к заметному сокращению шума в регистрируемом сигнале.

Как будет показано ниже, помимо шумов, связанных с попаданием прямых или рассеянных рентгеновских фотонов в отсек детектора флуориметра, регистрируемые шумы могут быть также, вероятнее всего, сформированы наводками в схеме фотоумножителя от высоковольтного кабеля, питающего рентгеновскую трубку. При этом измерения, проведенные в присутствии и отсутствие свинцового стекла, экранирующего фронтальное окошко внутреннего защитного кожуха, не демонстрируют заметной разницы в регистрируемом сигнале. С целью дополнительной защиты оптических элементов отсека детектора флуориметра фронтальная стенка отсека детектора может быть дополнительно экранирована ширмой из листового свинца $2 \mathrm{~mm}$.

\section{Пример результатов измерений XEOL-сигнала, оптимизация условий эксперимента}

Как было показано нами ранее [29], при расположении источника в плоскости окошка детектора флуориметра определяющее значение имеет расстояние от источника рентгеновского излучения до исследуемого образца, в то время как удаленность образца от детектора, регистрирующего оптическую флуоресценцию, оказывает заметно меньшее влияние на интенсивность регистрируемого сигнала.
Поэтому в новом варианте установки для измерения XEOL-сигнала была реализована конструкция с фиксированным положением образца относительно окошка детектора флуориметра и предусмотрена возможность варьирования расстояния от окошка рентгеновской трубки до исследуемого образца, с целью оптимизации уровня сигнала для различных образцов, в том числе в порошкообразной и жидкой форме (последние, ввиду существенно меньшей концентрации, демонстрируют более слабый XEOL-сигнал при прочих равных условиях эксперимента, рис. 4). Результаты тестовых измерений для коммерческого образца рентгеновского люминофора RC-450 приведены на рис. 7.

Можно видеть, что при вертикальном расположении рентгеновской трубки относительно отсека детектора флуориметра и уменьшении расстояния между окошком рентгеновской трубки и образцом интенсивность регистрируемого оптического сигнала существенно увеличивается. При этом ввиду высокой расходимости генерируемого рентгеновского пучка (угол раствора конуса $\sim 40^{\circ}$ ), даже при минимально возможном расстоянии $R$, вся поверхность исследуемых образцов $\sim 1 \times 1 \mathrm{~cm}^{2}$ остается равномерно засвеченной рентгеновским пучком. При этом стоит отметить, что $R=5.2 \mathrm{~cm}$ является минимально возможным расстоянием от окошка рентгеновской трубки до образца ввиду конструктивных особенностей разрабатываемой установки (наличия внутреннего защитного кожуха).

На следующем этапе при фиксированном значении расстояния от окошка рентгеновской трубки до образца $(R=5.2 \mathrm{~cm})$ были проведены тестовые измерения светимости порошкообразного коммерческого люминофора $\mathrm{RC}-450$ на основе сульфида цинка при варьировании тока и ускоряющего напряжения трубки. Полученный в результате теста сигнал представлен на рис. 8, $a, b$.

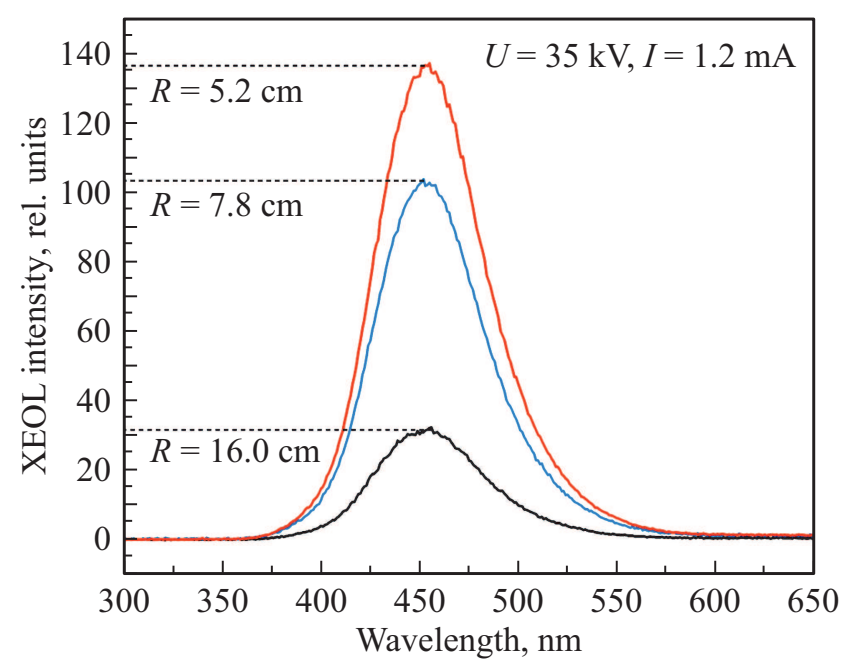

Pис. 7. Результаты измерений оптического отклика (XEOL-сигнала) для порошкообразного коммерческого люминофора RC-450 при варьировании расстояния от окошка рентгеновской трубки до образца. 

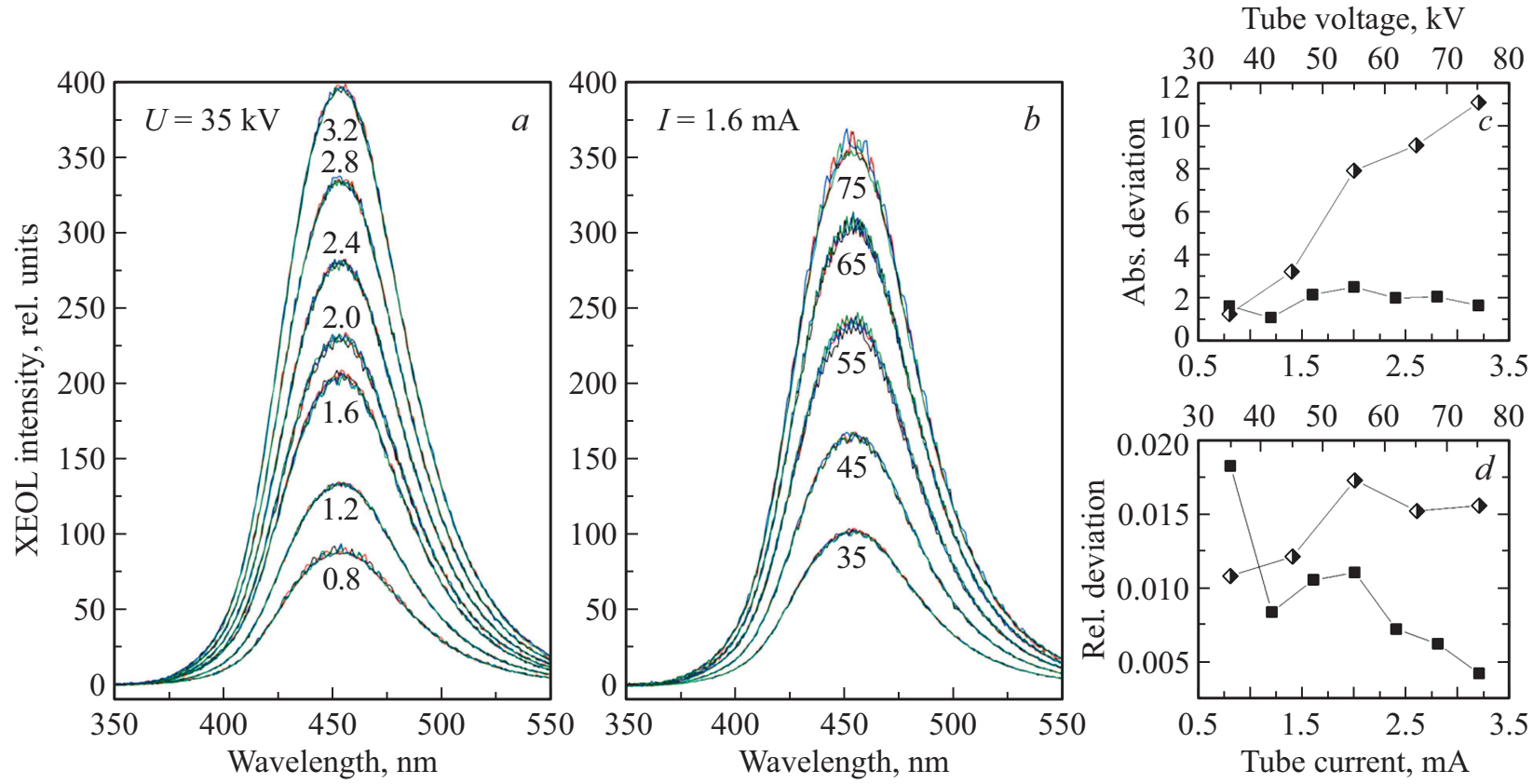

Рис. 8. Тестовые измерения оптического отклика (XEOL-сигнала) для порошкообразного коммерческого люминофора RC-450 (a) при варьировании тока трубки и фиксированном ускоряющем напряжение $U=35 \mathrm{kV}$ и $(b)$ при варьировании ускоряющего напряжения и фиксированном токе трубки $I=1.6 \mathrm{~mA}$. Варьируемые значения тока $(I)$ трубки и ускоряющего напряжения $(U)$ показаны под каждой кривой. Абсолютные $(c)$ и относительные $(d)$ отклонения значений интенсивности основного максимума флуоресценции, полученные результаты усреднения сигнала по результатам четырех измерений для каждой пары $(U ; I)$, при варьировании ускоряющего напряжения (полузакрашенные ромбы) и тока трубки (закрашенные квадраты).

С целью визуальной оценки качества регистрируемого сигнала приведены серии спектров, полученные для каждой пары значений ускоряющего напряжения $U$ и тока $I$ рентгеновской трубки (вместо результатов усреднения). С целью количественной оценки шума, присутствующего в регистрируемом сигнале, на рис. 8, $c, d$ продемонстрированы значения абсолютных и относительных отклонений, полученные при усреднении сигнала в области максимума - $454 \mathrm{~nm}$. Усреднение сигнала проводилось по результатам четырех измерений для каждой пары $U$ и $I$, в то время как значение абсолютного и относительного отклонений рассчитывалось как усредненное значение среднеквадратичного отклонения, посчитанного для 10 точек в области основанного максимума (в диапазоне длин волн 450-460 nm). Как по результатам визуальной, так и количественной оценки, можно заключить, что при необходимости увеличения интенсивности регистрируемого сигнала для малоконцентрированных образцов существенно лучшее соотношение сигнал/шум может быть получено путем увеличения тока трубки при фиксированных значениях ускоряющего напряжения в диапазоне $35-45 \mathrm{kV}$. В то время как дальнейшее увеличение ускоряющего напряжения до значений $55 \mathrm{kV}$ и выше приводит к заметному увеличению шума в регистрируемом сигнале.

Как было отмечено выше, заметное ухудшение качества сигнала наблюдается именно при увеличении ускоряющего напряжения трубки. Таким образом, можно заключить, что увеличение количества рентгеновских фотонов (при увеличении тока трубки, рис. 8,a) не оказывает заметного влияния на качество регистрируемого сигнала, в то время как увеличение энергии генерируемых рентгеновских фотонов (при увеличении ускоряющего напряжения трубки, рис. 8, $b$ ) приводит к заметному увеличению шума. Результаты наблюдений позволяют предположить, что регистрируемые шумы при высоких значениях ускоряющего напряжения трубки могут быть связаны либо с большей проникающей способностью высокоэнергетических фотонов (которые могут с большей вероятностью преодолевать свинцовый экран внутреннего защитного кожуха), либо с возможным наведенным электричеством в цепи фотоумножителя в схеме детектора флуориметра ввиду расположенного в относительной близости высоковольтного питающего кабеля рентгеновской трубки.

\section{Примеры измерений XEOL-cпектров наноразмерных ренгенолюминофоров в порошкообразной и коллоидной фазах}

В качестве примера измерений оптического отклика образцов люминофоров, разрабатываемых в качестве составных частей нанокомпозитов для рентгеновской фотодинамической терапии, в настоящем разделе представ- 


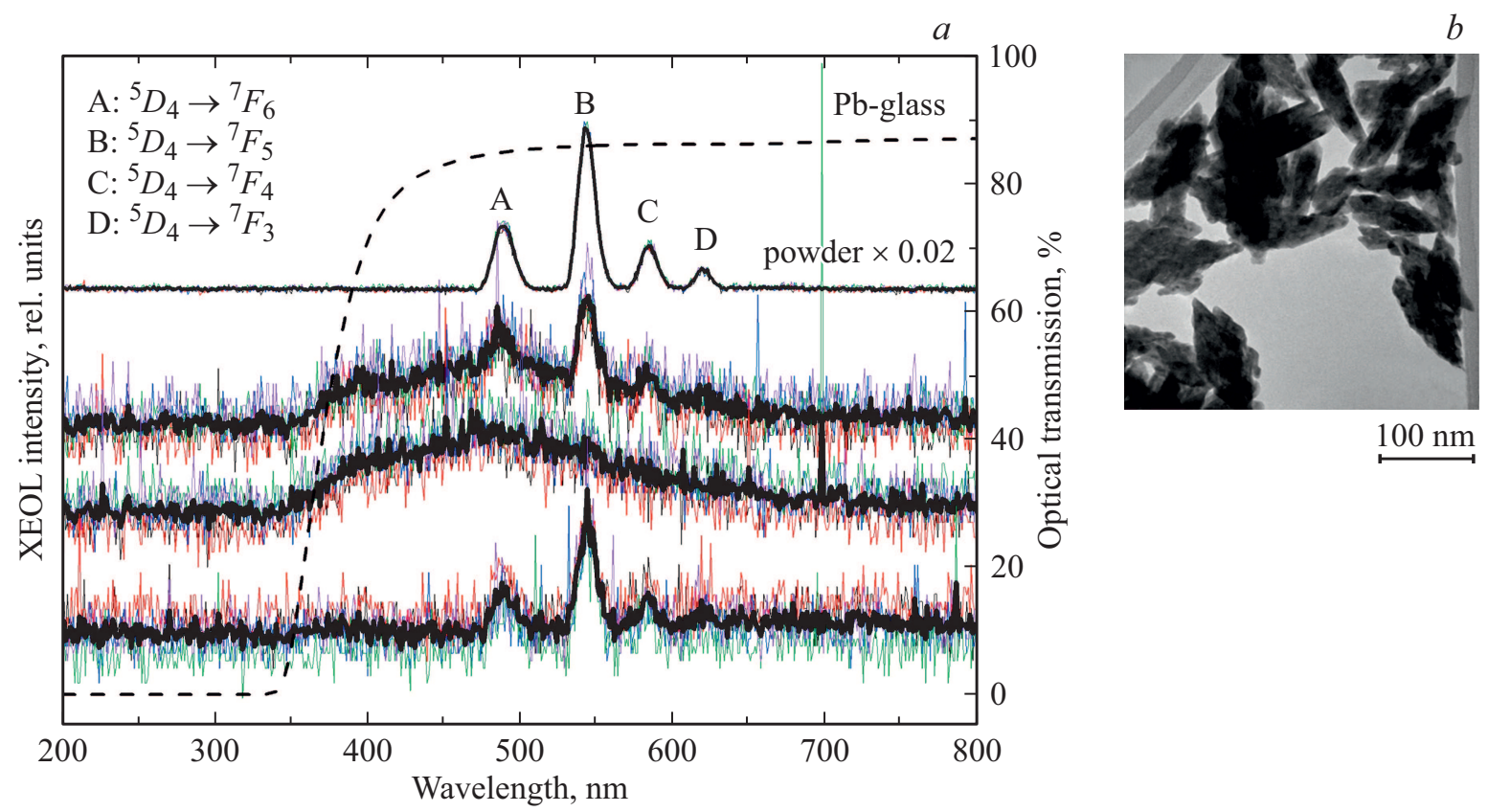

Pис. 9. (a) Пример измерения XEOL-сигнала для наноразмерного рентгеновского люминофора $\mathrm{GdF}$ : $\mathrm{Tb}(15 \%)$ в форме порошка (верхняя кривая) и в форме коллоидных растворов $(12 \mathrm{mg} / \mathrm{ml})$ сверху вниз: 1 - сигнал, полученный для коллоидного раствора в кварцевой кювете, 2 - сигнал, зарегистрированный от кварцевой кюветы без образца, 3 - сигнал, полученный для коллоидного раствора в пластиковой кювете. В левой верхней части рисунка обозначены атомные термы соответствующих переходов для ионов $\mathrm{Tb}^{3+}$. Правый нижний индекс соответствует квантовому числу полного углового момента, в то время левый верхний индекс обозначает мультиплетность терма, определяемую как $2 S+1$, где $S-$ результирующий спин. $(b)$ Снимок частиц люминофора, полученный на просвечивающем электронном микроскопе.

лены результаты измерений для образца $\mathrm{GdF}_{3}-\mathrm{Tb}(15 \%)$ в порошкообразной фазе и в форме коллоидного раствора. Образцы рентгенолюминофора $\mathrm{GdF}_{3}-\mathrm{Tb}(15 \%)$ были получены сольвотермальным методом синтеза путем смешивания солей гадолиния $\mathrm{GdCl}_{3}$, тербия $\mathrm{TbCl}_{3}$ и фторида $\mathrm{NH}_{4} \mathrm{~F}$. Изображения, полученные с помощью просвечивающей электронной микроскопии, показали формирование ромбоэдрических частиц с усредненным размером $\sim 50 \mathrm{~nm}$. Подробное описание методики синтеза и характеризации данного люминофора будет представлено в наших последующих работах. На рис. 9, $a$ представлены результаты измерений XEOL-сигнала исследуемого образца в порошкообразной форме. Можно видеть, что при облучении образцов рентгеновским пучком $(U=35 \mathrm{kV}, I=1.6 \mathrm{~mA})$ был зарегистрирован заметный выход флуоресценции. Регистрируемый сигнал имеет четыре основных ярко выраженных максимума, локализованных при длинах волн 488, 544, 584 и $621 \mathrm{~nm}$. Атомные термы, соответствующие данным переходам для иона $\mathrm{Tb}^{3+}$, обозначены на рис. 9. Для наглядности и оценки качества сигнала на рис. 9 представлены как результаты единичных измерений (время накопления $\sim 40 \mathrm{~s}$ на спектр) - разноцветные кривые, так и результат усреднения по 5 измерениям - черная кривая.

На рис. 4 представлены результаты измерений XEOL-сигнала для образца $\mathrm{GdF}_{3}: \mathrm{Tb}(15 \%)$ в форме коллоидного раствора, полученного с концентрацией $12 \mathrm{mg} / \mathrm{ml}$. Для получения стабильного коллоидного раствора порошок люминофора растворялся в дистиллированной воде, после чего подвергался ультразвуковой обработке в течение $20 \mathrm{~h}$. На рис. 9, $a$ представлен зарегистрированный XEOL-сигнал для исследуемого образца в кварцевой (кривая 1) и пластиковой (кривая 3) кюветах. Полученные результаты показали, что использование кварцевой кюветы является нежелательным при измерениях сильно разбавленных образцов, ввиду наличия фонового сигнала от материала кюветы (вероятно, обусловленного малым количеством примесей). Фоновый сигнал, регистрируемый при измерениях для кварцевой кюветы, заполненной дистиллированной водой, показан на рис. 9, $a$ (кривая 2). При этом даже при измерениях в пластиковой кювете для коллоидного раствора люминофора $\mathrm{GdF}_{3}-\mathrm{Tb}(15 \%)$ отмечается заметное уменьшение интенсивности в сравнении с порошкообразным образцом ввиду малой концентрации образца. Падение интенсивности при переходе от порошка к коллоидному раствору составляет приблизительно 1 порядок. Для наглядности на рис. 4 продемонстрирован также спектр пропускания оптического сигнала в диапазоне 200-800 nm для свинцового стекла, используемого для экранирования фронтального отверстия внутреннего защитного кожуха. Можно видеть, что отсутствие фонового сигнала кварцевой кюветы при длинах волн $<350 \mathrm{~nm}$ 
может быть обусловлено полным поглощением оптического сигнала в данной области за счет экранирующего $\mathrm{Pb}$-стекла.

Результаты измерений, представленные на рис. 4, были получены при большом удалении рентгеновской трубки от образца $(R \sim 16 \mathrm{~cm})$. Проблема слабого сигнала для разбавленных образцов может быть решена путем оптимизации расстояния от выходного окошка рентгеновской трубки до поверхности образца (рис. 7).

\section{Пример экспериментов с использованием портативного спектрометра OCEAN-FX}

Как отмечалось выше, при разработке материалов для рентгеновской фотодинамической терапии важную роль играет начальный этап - исследование оптического отклика рентгеновских люминофоров при возбуждении ионизирующим излучением. При этом в медицинской практике, в частности при стереоскопической радиохирургии - методе лучевой терапии, заключающемся в однократном облучении очага патологии высокой дозой сфокусированного ионизирующего излучения [14,15], зачастую используются гамма-лучи, обладающие большей энергией и высокой проникающей способностью. В частности, в настоящее время широко используются так называемые „гамма-ножи“, установки для радиохирургии, использующие множественные источники гамма-излучения на основе изотопов $\mathrm{Co}^{60}$ или линейных ускорителей электронов, фокусируемые в области патологии с помощью системы коллимирующих щелей.

С целью исследования оптического отклика разрабатываемых наночастиц рентгенлюминофоров на реальных гамма-установках, используемых в медицинских центрах, в настоящей работе была рассмотрена возможность регистрации сигнала с помощью портативного оптического спектрометра OCEAN-FX. Важно отметить, что в схеме детектирования данного спектрометра в отличие от флуориметра Cary Eclipse отсутствуют элементы, усиливающие оптический сигнал до его попадания на линейный кремниевый CMOS-детектор, ввиду чего чувствительность спектрометра OCEAN-FX существенно уступает чувствительности флуориметра Cary Eclipse.

Ввиду вышеобозначенных ограничений измерения XEOL-сигнала с помощью портативного оптического спектрометра OCEAN-FX производились с использованием оптоволоконного волновода, позволяющего регистрировать оптический выход в непосредственной близости от поверхности образца. Модернизированный держатель образца, позволяющий осуществить однозначное позиционирование волновода относительно поверхности порошкообразного образца, показан на вставке к рис. 4.

На рис. 4 представлены результаты измерений оптического отклика коммерческого люминофора RC-450, полученные с помощью спектрометра OCEAN-FX. В качестве источника ионизирующего излучения использовалась ранее описанная рентгеновская трубка РАП90-5. Ввиду меньшей оптической чувствительности спектрометра даже при использовании большого тока трубки $(I=3.5 \mathrm{~mA})$ и ускоряющих напряжений 55 и $75 \mathrm{kV}$ регистрируемый сигнал оказывается значительно более слабым в сравнении с детектированием с помощью стационарного флуориметра Cary Eclipse. C другой стороны, благодаря возможности использования оптического волновода длиной $2 \mathrm{~m}$ сам спектрометр OCEAN-FX оказывается защищенным как от попадания в область детектора рассеянных рентгеновских фотонов, так и от возможных электрических наводок от высоковольтного силового кабеля, питающего рентгеновскую трубку.

Стоит отметить, что при использовании данной схемы детектирования в экспериментах, где в качестве ионизирующего излучения планируется использование установок типа „гамма-нож“, благодаря более высокой энергии гамма-излучения и сфокусированности ионизирующего излучения следует ожидать улучшения соотношения сигнал/шум в регистрируемом сигнале.

\section{Заключение}

В настоящей работе приведено детальное описание конструктивных особенностей разработанной установки для регистрации XEOL-сигнала для исследования рентгеновских люминофоров в качестве компонент нанокомпозитных материалов для рентгеновской фотодинамической терапии. Показано, что в результате дополнительного экранирования элементов флуориметра от проникающего рентгеновского излучения удается существенным образом сократить шумы в регистрируемом сигнале. В работе приведены результаты тестовых испытаний установки при варьировании тока и ускоряющего напряжения рентгеновской трубки, используемой в качестве источника ионизирующего излучения. Обсуждено влияние данных параметров на соотношение сигнал/шум. Приведены примеры регистрации XEOL-сигнала, полученного для наноразмерных рентгенлюминофоров на основе наночастиц $\mathrm{GdF}_{3}: \mathrm{Tb}$ в порошкообразной форме и в виде коллоидного раствора. Обсуждены пути оптимизации эксперимента для регистрации более качественного сигнала для разбавленных образцов.

\section{Благодарности}

Данное исследование было выполнено при поддержке Российского научного фонда (проект № 19-15-00305).

\section{Конфликт интересов}

Авторы заявляют, что у них нет конфликта интересов. 


\section{Список литературы}

[1] E. Panzarini, V. Inguscio, L. Dini. Int. J. Photoenergy, 2011, 713726 (2011).

[2] Z. Luksiene. Medicina (Kaunas). 39, 1137-1150 (2003).

[3] R.L. Lipson, E.J. Baldes. Archives of Dermatology, 82, 508-516 (1960).

[4] T.J. Dougherty, J.E. Kaufman, A. Goldfarb et al. Cancer Res., 38, 2628-2635 (1978).

[5] L. Larue, A. Ben Mihoub, Z. Youssef et al. Photochem. Photobiol. Sci., 17, 1612-1650 (2018).

[6] W. Fan, P. Huang, X. Chen. Chem. Soc. Rev., 45, 6488-6519 (2016).

[7] X. Wen, Y. Li, M.R. Hamblin. Photodiagnosis Photodyn. Ther., 19, 140-152 (2017).

[8] J. Akimoto. Neurologia medico-chirurgica, 56, 151-157 (2016).

[9] J.S. Friedberg. J. Natl. Compr. Canc. Netw., 10, S-75-S-79 (2012).

[10] B.W. Pogue, B.C. Wilson. J. Biomed. Opt., 23, 121610 (2018).

[11] D. Orsi, D. Bernardi, G. Giovanardi et al. Colloids Interface Sci. Commun., 39, 100327 (2020).

[12] A. Belanova, V. Chmykhalo, D. Beseda et al. Photochem. Photobiol. Sci., 19, 1134-1144 (2020).

[13] S. Schwartz, K. Absolon, H. Vermund. Univ. Minn. Med. Bull., 27, 1-37 (1955).

[14] L. Leksell. Acta Chir. Scand., 102, 316-319 (1951).

[15] L. Leksell, B. Larsson, B. Andersson et al. Acta Radiologica, 54, 251-264 (1960)

[16] L. Leksell, J. Neurol. Neurosurg. Psychiatry, 46, 797-803 (1983).

[17] V. Helms. Principles of Computational Cell Biology: From Protein Complexes to Cellular Networks (Wiley, 2008).

[18] A. Jurgensen. Can. J. Chem. 95, 1198-1204 (2017).

[19] T.K. Sham. J. Electron Spectrosc. Relat. Phenom., 204, 196-207 (2015).

[20] M. Peng, Y. Li, J. Gao et al. J. Phys. Chem. C, 115, 11420-11426 (2011).

[21] T. Paik, T.R. Gordon, A.M. Prantner et al. ACS Nano, 7, 2850-2859 (2013).

[22] M.J. Ward, P.A. Rupar, M.W. Murphy et al. J. Phys. Conf. Ser., 430, 012046 (2013).

[23] D. Zhang, H. Zhang, X. Zhang et al. Phys. Chem. Chem. Phys., 18, 6406-6410 (2016).

[24] R.L. Owen, B.A. Yorke, A.R. Pearson. Acta Crystallogr. D, 68, 505-510 (2012).

[25] H. Chen, T. Moore, B. Qi et al. ACS Nano, 7, 1178-1187 (2013).

[26] J.F.W. Mosselmans, R.P. Taylor et al. J. Phys. Conf. Ser., 425, 182009 (2013)

[27] M.J. Ward, W.-Q. Han, T.-K. Sham. J. Phys. Chem. C, 115, 20507-20514 (2011).

[28] Z. Wang, X. Guo, T.-K. Sham. Nanoscale, 6, 6531-6536 (2014).

[29] М.А. Солдатов, П.В. Медведев, В.В. Бутова и др. Поверхность. Рентгеновские, синхротронные и нейтронные исследования, 1, 10-14 (2021).

[30] S. Clement, W. Deng, E. Camilleri et al. Scientific Reports, 6, 19954 (2016). 